\title{
Managing Meaning: Language and Technology in Academic Libraries
}

\author{
Daniel Coffey and Karen Lawson
}

\begin{abstract}
Professionals in academe today are faced with an ever-increasing number of technological advances, and few feel the effects of these changes more than library professionals. With each change comes a new vocabulary that has the potential to cause communication rifts between departments in academic libraries. Through a comprehensive literature review and a selective survey of administrators of information technology, public services, and technical services in academic libraries belonging to the Association of Research Libraries, the authors show how the new terminology has affected communication among professionals in these positions, specifically in the context of technological decisionmaking, and ideas are put forth for ways to overcome this problem.
\end{abstract}

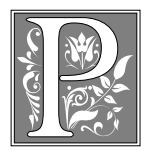

rofessionals in academe today are faced with an ever-increasing number of technological advances, and few feel the effects of these advances more than library professionals. With each advance comes a new vocabulary that has the potential to cause communication rifts between academic library departments. Because of the nature of their jobs and the increasing pervasiveness of technology, library professionals in information technology or instructional technology (IT) units have the potential to hold an upper hand in library discussions concerning technological issues. Do they also have a responsibility to ensure that colleagues in other areas of the library understand the technological terminology being used in these discussions? Although there is some current research dealing with the effects of communication patterns and hierarchies themselves, there is a lack of published research on how technologically related meaning change affects communication leading to decision-making.

Many of us can remember clearly the days when a brick wall separated computing services and the rest of the library. The Systems Office was considered the "back office," or even part of another unit outside the library that administered all computing functions on campus. Using technology for any purpose other than making certain processes more efficient by automating them was largely foreign to academic professionals. In 1990, Jonathan S. Intner offered this advice:

The main problem academics experience in dealing with techies is an inability to communicate successfully. Techies speak a language that can be quite difficult for those out-

Daniel Coffey is the Languages and Literatures Librarian at Iowa State University Library; e-mail: dcoffey@iastate.edu. Karen Lawson is the Interim Information Technology Officer at Iowa State University Library; e-mail: klawson@iastate.edu. 
side their cohorts to understand, which is also true of people in any academic discipline. The disparate backgrounds of the techies and academics result in different perspectives. And, in order for effective communication to take place, all the parties involved must be ready to make an effort to make themselves understood. Mutual respect between the parties involved in the discussion is critical for any meaningful communication to take place. ${ }^{1}$

In less than a decade, the lines of demarcation have become blurred and libraries frequently support their own IT units. Although there are still "techies," they no longer exist in a stand-alone role, and although simple systems are not extinct, they coexist with increasingly elaborate systems.

\section{Background and Literature Review}

The issue of technological terminology in librarianship lies between the academic fields of linguistics and rhetoric/communication. New vocabularies, when they include words previously understood to mean something else, illustrate the linguistic issue of meaning change. Difficulties may arise when members of different departments in the library, with presumably different needs and agendas, attempt to use these newly altered words to state their positions to their colleagues and superiors. We must first turn to linguistics to understand the nature of the change and then to rhetoric/communication studies to understand how these changes put library professionals at either an advantage or a disadvantage in technological discussions.

Language, like everything else, gradually transforms itself over time, and linguists have historically found the concept of meaning change to be problematic. According to linguist Jean Aitchison, fears about meaning slippage have been recorded since the fifth century B.C. ${ }^{2}$ Semantics, or the "science of meaning," be- gan to be studied in earnest in the early nineteenth century and encompassed attempts at both enumerating types of changes and exploring causes of meaning change. By the first half of the twentieth century, structural linguistics had evolved to consider words not as isolated fragments but, rather, as part of a mesh of surrounding words. Polysemy is the term used to discuss the concept of a word having multiple meanings that evolve alongside existing ones. Words may develop several layers as new meanings superimpose themselves on top of the older ones.

Aitchison also stated: "early attempts to catalogue meaning change were mostly discouraging. In recent years, however, insights as to how it happens are leading to a greater understanding ... of how language works today." ${ }^{3}$ The relative surge of interest among contemporary linguists in the topic of meaning change led the authors to turn to the online Ask a Linguist Forum. ${ }^{4}$ The following question was posed: Advances in technology include the layering of new meaning over old words (e.g., virus, alias, domain). Technological decisions that are being made presuppose an understanding of these new meanings. How do you see this affecting the "power" structures of traditional organizations, such as academe? To the linguists who responded, a follow-up question was asked: How do you see this affecting the decision-making processes in hierarchical organizations, where some of the players, on any given level, may or may not possess an understanding of the new layers of meaning?

Suzette Haden Elgin commented:

The fact that people in traditional organizations will be hearing terms and understanding them to have their traditional meaning-instead of the 'new' meaning-is going to create major communication breakdowns and misunderstandings, in decision-making processes and elsewhere .... It's what happens in any situation where people in language 
interactions are using a single word with more than one meaning and are taking it for granted (incorrectly) that everyone shares the same meaning. The meanings you've labeled 'new' are new because they are the jargon of particular fields, and using jargon is always dangerous. $^{5}$

\section{Deborah Ruuskanen added:}

My personal opinion, for which I have no scientific basis whatsoever, is that the 'Old Guard' in academe never bother to learn the 'new meanings' and make decisions based on political considerations rather than a true understanding of what is involved. This is a rather cynical viewpoint, based on observations of fields like medicine, where decisions are often made by administrators, not scientists, over a period of 30 years. ${ }^{6}$

Perhaps it would be less confusing if all new technological terms were created, as it were, from scratch. Unfortunately, meaning change is a messy process that involves the layering of meanings upon words, often by a logical process, but nevertheless equipping a given term with a radically different meaning to wear alongside its more traditional definitions. In 1999, Anne Marie Candido advised: "librarians are succumbing to the influence of the easy-to-adopt, prefab, impersonal, ugly, and often impenetrable jargon borrowed from business and computer technology." ${ }^{\prime 7}$ Technological statements such as "the enterprise administrator can control all the forests and trees" or "resetting the auditing entries on all child objects will enable the propagation of inheritable auditing entries, ${ }^{\prime 8}$ which consist of a series of common words, can still be unintelligible to some participants in a technological discussion.

The problem of meaning change with regard to technological terminology becomes more complex when viewed in the contexts of communication and rhetoric. The use and understanding of these new terms play a crucial role in determining the outcomes of decision-making discussions. In the aptly named New York Times article by John Schwartz, "Language Heads Down the Rabbit Hole," Michael Schrage, codirector of the e-markets initiative at the Media Laboratory of the Massachusetts Institute of Technology warned that: "when the same word means different things to different people, you're going to spend more time managing meaning than managing the problem."

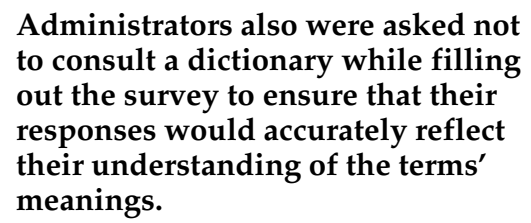

Stuart MacDonald defined two types of players in what he refers to as information "regimes": gatekeepers and experts..$^{10}$ Both are concerned with acquiring information-the gatekeeper to distribute among people in different areas of the regime, and the expert for his own edification. The expert is expected to be interested in acquiring information that will support his or her specialized knowledge. The gatekeeper's value lies in his or her ability to distribute internal information to other parts of the organization that most need to use the information. Taking MacDonald's two types and applying them to our academic library scenario, we can see different sorts of possible problems and solutions. Library professionals in all areas of a library strive for an expert's grasp of knowledge in their field. In interdepartmental library discussions, too much of an expert mentality can result in a lack of interest in ensuring that ideas are sufficiently understood by a speaker's audience, and also little motivation on the part of the listenerexpert to understand concepts that fall outside their narrow professional scope of interest. 
This gatekeeper/expert conundrum fits, more specifically, in our study of the pitfalls of technological library discussions with regard to IT departments. They are responsible for fully understanding the meanings and implications of relevant technological terminology. Are they also responsible for making sure that library staff possess a level of understanding of these terms sufficient for them to engage in decision-making processes? It makes sense to encourage library staff to view expertise within a library department or division as the norm and gatekeeping as a role to play when needed. If so, IT professionals must be able to alter their roles from gatekeeper to expert and back, as appropriate, when engaged in technological discussions with non-IT staff.

Matt Holland also made reference to "boundary-spanning individuals" who have the "ability to understand and interpret the local language of the source and represent that information in the language of the recipient." ${ }^{\prime 11}$ As they are necessary conduits through which changes will be accepted by a larger group, Holland stresses that it is the responsibility of the change agent (expert) to seek out and actively use boundary-spanners. Although MacDonald sees everyone with the potential to function as a gatekeeper, Holland's boundary-spanning individual has the additional attributes of being a star communicator and highly regarded professional.

MacDonald's gatekeeper/expert model is based largely on a presupposed existence of altruism, which does not take into account the attitudes in academic libraries brought on by the political climate in academe. Thus, another important variable in the technology-language equation can be power. Focusing simultaneously on technology, language, and power in libraries parallels the "thousands of minidramas reenacted every day in lawyers' offices, police stations, and courthouses around the country. The dominant element in almost every one of these minidramas is language. To the extent that power is realized, exercised, abused, or challenged in such events, the means are primarily linguistic." ${ }^{\prime 2}$

With the growing need for online access to bibliographic resources and the widespread adoption of the Internet, both at home and within organizations, the relationship between IT and the library has changed. These changes involve issues of environment, communication, leadership and learning, in all of which languagespecifically, the new terminologiesplays a crucial role. Mark Warschauer wrote:

Literacy is frequently viewed as a set of context-neutral, value-free skills than can be imparted to individuals. A study of history, though, shows this model of literacy to be off the mark.... Rather, technological change intersects with other social, economic, cultural, and political factors to help determine how literacy is practiced..$^{13}$

\section{In 1997, Gregory A. Crawford and} Ronald E. Rice discussed theories of organizational structure and power and constructed a model for organizational power and technology within liberal arts colleges. ${ }^{14}$ A study done by Hong $\mathrm{Xu}$ looked at type and level of position in academic libraries related to communication behavior. ${ }^{15}$ Research on the combination of language and technology in academic libraries has not been forthcoming.

\section{Methodology}

On March 19, 2001, a survey was mailed to each administrator of technical services (TS), public services (PS), and information technology at fifty ARL academic libraries. For the purposes of this study, the authors were interested in reaching libraries where the three aforementioned departments were not integrated. Therefore, an institution was selected for inclusion in the survey if the library's administrative structure appeared, from information displayed on the library's Web site, to break down into these three areas in an easily identifiable fashion. Also for the 
TABLE 1

Perceived Frequency of Alienation from the Technological Decision-making Process Because of Terminology

\begin{tabular}{|c|c|c|c|c|c|c|c|c|c|c|c|}
\hline \multirow[t]{3}{*}{ Area of Administration } & \multirow[b]{3}{*}{$\mathbf{n}$} & \multicolumn{8}{|c|}{ Frequency of Response } & & \\
\hline & & \multicolumn{2}{|c|}{ Always } & \multicolumn{2}{|c|}{ Often } & \multicolumn{2}{|c|}{ Sometimes } & \multicolumn{2}{|c|}{ Seldom } & \multicolumn{2}{|c|}{ Never } \\
\hline & & $\mathbf{n}$ & $\%$ & $\mathbf{n}$ & $\%$ & $\mathbf{n}$ & $\%$ & $\mathbf{n}$ & $\%$ & $\mathbf{n}$ & $\%$ \\
\hline Information Technology & 28 & - & - & - & - & 1 & 4 & 9 & 32 & 18 & 64 \\
\hline Public Services & 24 & - & - & - & - & 8 & 33 & 15 & 63 & 1 & 4 \\
\hline \multicolumn{12}{|l|}{ Public Services and } \\
\hline Information Technology & 10 & - & - & - & - & 2 & 20 & 6 & 60 & 2 & 20 \\
\hline Technical Services & 20 & - & - & 1 & 5 & 10 & 50 & 6 & 30 & 3 & 15 \\
\hline \multicolumn{12}{|l|}{ Technical Services and } \\
\hline Information Technology & 5 & - & - & - & - & 1 & 20 & 3 & 60 & 1 & 20 \\
\hline All others & 7 & - & - & - & - & 2 & 29 & 3 & 43 & 2 & 29 \\
\hline
\end{tabular}

purposes of this study, Public Services as a departmental title may have included collection development, reference, or interlibrary loan; Technical Services may have included cataloging, acquisitions, or preservation/conservation; and Information Technology may have included automated systems, media equipment services, or instructional technology.

The survey instrument was composed of twenty-four categorical questions and one open-ended question that sought to assess the impact of technological terminology in selective U. S. ARL academic institutions to determine whether library administrators are at an advantage or disadvantage when participating in technology-related decision-making processes in their libraries. The cover letter sent with the survey included an instruction that allowed an administrator to refer the questionnaire to another person if he or she felt that person was in a more appropriate position to answer the survey questions. Administrators also were asked not to consult a dictionary while filling out the survey to ensure that their responses would accurately reflect their understanding of the terms' meanings. In addition to position-related information, specific inquiries were made to assess the understanding of a variety of technological terms; the perceived nature of technology-related discussions and decision- making in these libraries; the level of confidence the administrator had in his or her library director/dean's understanding of the technological terms presented; and the assumption of knowledge about technology-related terms that might or might not be occurring among groups of decision makers. Distinctions between academic statuses of the administrators were not queried (i.e., faculty/nonfaculty, MLS/non-MLS). Results are presented as proportional analyses using the calculation of frequencies and percentages.

\section{Results}

Ninety-five responses from the 150 administrators contacted yielded a total of ninety-four usable surveys, for a final return rate of 63 percent. Not every respondent answered every question; therefore, frequency data are given, as necessary, in the text. Of the ninety-three respondents, twenty-four (26\%) were PS administrators, twenty-eight (30\%) were IT administrators, and twenty (21\%) were TS administrators. The remaining respondents were administrators in charge of a combination of public services and information technology $(n=10)$, technical services and information technology $(n=5)$, and a combination of disparate library areas $(n=7)$, which represented 11,5 , and 7 percent of the respondents, respectively. 
In trying to assess the overall atmosphere of technology-related discussions, questions were posed about whether the respondents found these discussions at their institutions to be collegial, frustrating, intimidating, spirited, or difficult. A large majority of respondents found the discussions "collegial" $(90 \%, \mathrm{n}=80)$ and / or "spirited" $(81 \%, n=73)$. More than half of the respondents found the discussions "difficult" $(56 \%, \mathrm{n}=49)$, and half found them "frustrating" $(50 \%, \mathrm{n}=44)$. Fourteen respondents (16\%) found the discussions "intimidating." Thirty-five (39\%) of the respondents felt that IT discussions in their library were both "collegial" and "frustrating," and forty (45\%) felt that were both "collegial" and "difficult."

When asked whether they felt alienated from the technological decision-making process in their library because they did not understand the terminology being used, sixty-nine $(74 \%)$ responded "seldom" $(45 \%, n=42)$ or "never" $(29 \%$, $\mathrm{n}=27)$. (See table 1.)

When asked whether they assumed that their listeners had the same level of understanding as they did during technological discussions, most respondents indicated that they did "some of the time" $(79 \%, n=69)$ or "never" $(20 \%, n=25)$. (See table 2.)

Respondents were asked whether they could think of an example that would il- lustrate their answer to either the question about the nature of technological discussions in their library or the question about their perceived level of alienation from the technological decision-making process. Forty-eight percent of the respondents answered yes. IT professionals provided the largest number of responses (31\%), followed by public services $(29 \%)$, technical services (25\%), IT /PS (10\%), and IT /TS (4\%).

The administrators also were presented with fifteen terms and asked to rank their relative level of understanding (very well, somewhat, not at all) of the technological meaning of the terms. Several survey terms (alias, UPS, portal, client/server, attribute, push technology, domain, and backbone) are common words, acronyms, or phrases that currently have a technological "layer." Intranet is a technology term that is "layered" on Internet, another technology term. Additional terms composed of common words or symbols (evergreen, forest/trees, can, e-sign, P2P) were added because of their multiple appearances in nonlibrary technology-related literature between the months of November 2000 and February 2001. The last term questioned how well the respondents felt they would be able to explain the concept of bibliometrics to a colleague. The term bibliometrics is used among librarians to

TABLE 2

Perceived Frequency of Assumptions Concerning Levels of Understanding of Listeners in Technology-related Discussions

Area of Administration

Frequency of Response

\begin{tabular}{|c|c|c|c|c|c|c|c|}
\hline & \multicolumn{3}{|c|}{ All of the Time } & \multicolumn{2}{|c|}{ Some of the Time } & \multicolumn{2}{|c|}{ Never } \\
\hline & $\mathbf{n}$ & $\mathbf{n}$ & $\%$ & $\mathbf{n}$ & $\%$ & $\mathbf{n}$ & $\%$ \\
\hline Information Technology & 28 & 0 & 0 & 17 & 61 & 11 & 39 \\
\hline Public Services & 24 & 0 & 0 & 20 & 83 & 4 & 17 \\
\hline \multicolumn{8}{|l|}{ Public Services and } \\
\hline Information Technology & 10 & 0 & 0 & 9 & 90 & 1 & 10 \\
\hline Technical Services & 20 & 0 & 0 & 17 & 85 & 3 & 15 \\
\hline \multicolumn{8}{|l|}{ Technical Services and } \\
\hline Information Technology & 5 & 0 & 0 & 5 & 100 & 0 & 0 \\
\hline All others & 7 & 0 & 0 & 1 & 14 & 6 & 86 \\
\hline
\end{tabular}




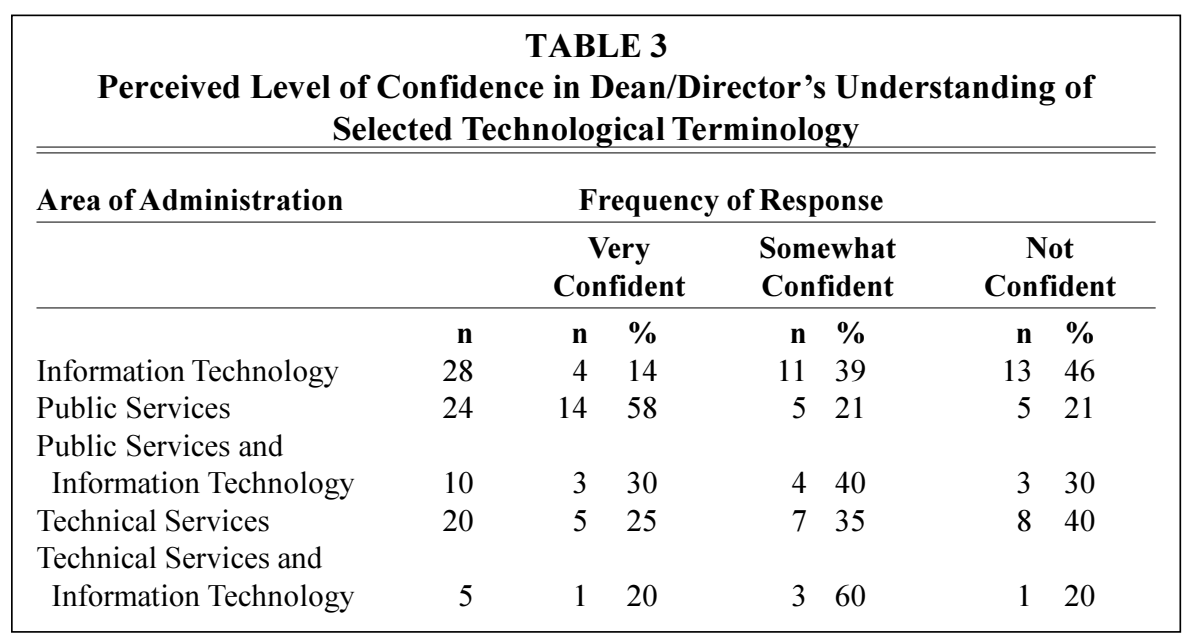

study the statistics of usage of materials and services within a library. The authors included it as a counterweight to gauge the general level of understanding of a nontechnical, but highly bibliographic, term among those surveyed.

The most frequently recognized term was Intranet, with a recognition level of "very well" across all administrators at 88 percent, followed by client server $(85 \%)$, domain and backbone $(78 \%)$, alias $(76 \%)$, portal $(73 \%)$, UPS $(70 \%)$, push technology (63\%), attribute (48\%), bibliometrics $(26 \%)$, P2P $(26 \%)$, forest/ trees $(12 \%)$, e-sign $(10 \%)$, can $(5 \%)$, and evergreen (4\%). Recognition levels for all terms, except bibliometrics, were highest among IT professionals (72\%). The next highest levels of recognition were administrators of public services and information technology $(60 \%)$ and administrators of technical services and information technology (52\%).

The majority of terms taken from nonIT literature (P2P, e-sign, forest/trees, evergreen, and can) had the lowest level of understanding among all administrators. Even among IT administrators, a level of understanding of "very well" for these terms was under 50 percent (P2P $44 \%$, esign $29 \%$, forest/trees $18 \%$, evergreen $11 \%$, can $7 \%$ ).

Bibliometrics was understood by administrators in opposite proportions from the strictly technological terms. Sixty per- cent of TS administrators felt they would be able to explain the concept of bibliometrics to a colleague "very well," followed by PS administrators (38\%), administrators of PS/IT and TS/IT (20\%), and IT administrators (18\%).

Administrators also were asked how confident they were that their library director/dean understood many or most of the same terms previously described. IT professionals indicated the lowest levels of confidence; 46 percent were "not confident" that their director or dean would understand the terms, and 39 percent were only "somewhat confident." (See table 3.)

\section{Discussion}

Jargon is a part of all professions. It is inclusive for those within the profession and can be exclusionary to those outside the profession by making them feel uncomfortable on their own turf. A 1991 study cited by David Tuffley found that "in a survey of IS (Information Science) directors, $46 \%$ reported that the culture gap between IS professionals and business counterparts was their most important challenge." ${ }^{\prime 16}$ A decade later, what are some of the language-related gaps that exist between IT professionals and their library counterparts?

When asked about the nature of technology discussions at their libraries, administrators described a wide variety of 
technology-related projects that were under discussion at their institutions. These included selection of new library management systems, wireless technology, metadata, self-checkout of materials, PCand server-related issues, digital librar-

\section{It is very important, as more than one administrator noted, to keep asking until you understand.}

ies, choosing between sophisticated software applications, XML, e-mail clients, Web portals, and database generated Web pages. As might be expected, IT professionals seldom or never felt alienated from the technological decision-making process in their libraries because of terminology and, to a great extent, neither do other library administrators. Heads of technical services were the only group who, a majority of times, even "sometimes" felt alienated (table 1). On the other hand, a high proportion of administrators had below a fifty percent recognition level for nearly half of the technological terms identified in the survey, and the authors received only one comment on the low level of confidence of IT administrators in their dean/director's level of understanding of technological terminology, and that was: "but why does that matter?"

Although the words themselves do not appear to be perceived as a problem for library administrators, how the words are used is definitely an issue for the administrators who gave an example that would illustrate their answer to either the survey question about the nature of technological discussions in their library or the question about their perceived level of alienation from the technological decision-making process.

Some comments received from IT administrators were: "I am often put in the position of 'translating' technological terms. The frustration comes in trying to explain complex processes in simple terms. Sometimes the process is just very complex and cannot be explained in easyto-understand terms," and "Everyone re- treats to those things with which they are familiar." One non-IT administrator felt that:

Sometimes I understand the terms, but not the implications of a particular decision. The problem has more to do with my weaker general computer technical background, the systems person's very precise use of terms and expert knowledge of context, and our different communication styles as opposed to my lack of knowledge of specific terms, and I am pretty assertive in making others explain the terminology they use. The problem for me is when the explanation itself is put in technical terms.

\section{Another administrator reported:}

Miscommunication stemmed from misunderstanding jargon on both sides and from assumptions (unspoken) on the part of each group. Because they all work in the same library, each group assumed they were talking from a common ground-but the 'postmortem' on the project showed they were not. It was not only the tech jargon that got in the way, but also mental models (or views of the world) that each group has.

The mental models mentioned in the paragraph above are the most frustrating issue for many IT administrators who are trying to communicate about technologyrelated issues. A mental model is a deeply held internal image of how the world works or how it should work. Heard from more than one IT administrator was a variation on: "Funny how users LOVE standards for library concerns, but not for technology. They want what is comfortable. That's what I see as difficult." Another striking language dichotomy that was described frequently is related to the installation or use of an automated process or software package. IT administra- 
tors frequently hear from non-IT library staff about software that is used in another institution that the IT administrator believes, for technical or systems reasons, would not work locally. One non-IT administrator explained the problem from the staff point of view: "It is frustrating when the systems person gives a really long, technical explanation of why we can't do something, even though I know other libraries (or other organizations) are able to do what I'm talking about."

Other important issues are clearly those of participation and/or listening. One non-IT administrator had this response: "Talk about servers/capacity/ proxy while I understand it, it takes little for me to drift if the topic discussed lasts TOO long." Another administrator stated:

\section{I am not always familiar with the technological terms spoken about in meetings and yet don't want to take the meeting time to ask if others do know. So I usually get through it and try to ask questions later. I do think this can often be a less-than- ideal way to participate (or not) in the meeting discussions.}

This is an insidious problem in technological discussions. Sik Hung $\mathrm{Ng}$ and James J. Bradac stated:

Given the interactional nature of con-
versation, the power of casting,
speakership, and topic control is con-
tingent on the continued presence of
hearers who remain in the conversa-
tion either by choice or as a result of
being kept there by others. Exit from
the physical setting of the conversa-
tion may be the only available
counterpower that is left for an indi-
vidual who is unwilling or unable to
engage in a verbal fight.... In most ev-
eryday conversation, hearers make a
psychological exit while remaining
silent when talk is expected. ${ }^{17}$

It is very important, as more than one administrator noted, to keep asking until you understand. Asking questions not only clarifies a particular point, but also can lead to a broader understanding of complex issues. One administrator stated:

Whenever we are discussing new technologies, it is inevitable that some know more than others, so it is frustrating. Some think they know more and better, so discussions can be spirited and difficult. But in the end, we're collegial because we're all in this together!

Participation in discussions is a necessary component of collegiality. The gatekeeper approach appears to be a necessary feature in an academic library cul-

\section{Successful librarians are experts in their field who are able to shed their "expertness" (not expertise, but the attitude of expertise) in order to truly serve, and not alienate, their clientele.}

ture so that administrators can make progressive technological decisions based on effective discourse. Conversely, the expert seems to be the culprit that keeps academic library administrators from being able to fully participate in technological discussions.

One IT administrator supported the gatekeeper model with the statement: "We work together in a collegial way because ... tech people generally depend upon each other's knowledge in areas of need." This respondent is presumably only referring to collegiality and gatekeeping within the circle of IT staff but states elsewhere in his response that his "background is not technical," and therefore he "depends upon the technical staff for advice and expertise in tech areas". It is an extra step for gatekeepers to perform the same function for staff in different departments. Another respondent, who is the administrator for both IT and PS areas, makes the claim that "technology moves forward so rapidly, there is always some realm where I feel uninformed." Where an expert might reinforce that feeling of being uninformed, 
this respondent is lucky enough to be working with gatekeepers, as evidenced by the next sentence in the response: "Our tech people, though, are patient and capable of defining, explaining, clarifying." It is logical to conclude that dependability in providing information to users is important and so is the manner is which the information is delivered.

The quotes in the paragraph above illustrate the benefits to be had by using the gatekeeping approach; they all define a problem, some variation on the lack of necessary information on the part of the respondent, and a solution, the information made available by the library staff member(s) who play the gatekeeper role. Other respondents illustrate the negative effects that an expert can have on discussions and decisions. The following quotes illustrate the same type of problem, but lack a solution. "When our AD for systems explains proposed projects, he often talks to the rest of us as if we are idiots and/or children" is a description by a administrator of a colleague playing only the role of expert. Another administrator claims to "understand the terms, but not the implications of a particular decision." One of the reasons for this lack of understanding, according to the administrator, is "the systems person's very precise use of terms and expert knowledge of context." Expert knowledge, so useful in certain contexts, is of little help in the effective transferal of that knowledge.

Administrators find discussions frustrating when IT staff equate technological readiness with organizational or user readiness. Paul Rux wrote:

Incremental change is negotiated. It goes step by step. It co-opts opposition by offering benefits to the opponents. It takes longer, but incremental change reduces the danger of being blown out of the water in the process of introducing new ideas and new technology. ${ }^{18}$

In the context of this article, much of the responsibility for adopting the role of gatekeeper in technology-related discussions lies with IT staff. It is important to note that several of the responses from IT administrators show that they, too, benefit from library staff who act as gatekeepers for their departments or divisions.

\section{Conclusion}

For readers in the United States, there is hardly a more evocative word than cookie. It is redolent of taste, smell, and a kindly family member who produces the morsel of goodness for comfort and pleasure. Other than a poorly prepared one, could a cookie put you at risk? Yes, if the "cookie" is information that a Web site puts on your computer's hard disk so that it can remember something about you at a later time. Can a cookie be a verbal barrier? Yes, if as a word, it is used in a conscious or unconscious way to deny access to information in a decision-making situation. In this example, the word cookie has taken on a technological meaning through "layering." If the context in which the word is used puts a discussion beyond the range of any participant, the decisionmaking process will suffer.

The intertwining of words, language, and communication to create a positive environment for any type of decision-making process is important. In most institutions, an organization and a hierarchy were established long before it was necessary to create a technology infrastructure to support them. Frequently, people find a way to work around what is existing rather than building technology into the way people work. It is interesting to note that the term most frequently recognized by library administrators in the authors' survey was Intranet. An Intranet, a private network that is contained within an organization's Web presence, is "where people are actually building things to assist their work on top of the existing network topologies.... It's something they're putting in."19 It is an example of users taking a piece of technology and making it fit their own needs.

Ultimately, the results of the survey discussed in this article call for a similar 
"verbal Intranet" to be laid over the existing topology of interdepartmental communication in academic libraries. Communication structures, in academic libraries as well as in all other venues of professional interaction, work well under normal circumstances. Each time a new communications medium has emerged, communication itself has evolved to fit the medium. Every new step in technology, whether a new medium or a change within a medium, has brought new ways of getting out the message. When the entrance of new terminology that has not yet been subsumed challenges them, it is the responsibility of the communicators to improvise a new communication structure that enables them to keep communicating, with the understanding that, in time, the "verbal Intranet" of new terminology will become indistinguishable from the familiar communication structure.

The results of the survey show a profound desire on the part of library administrators to understand, and to promote understanding of, the new technological terminology. This is not surprising. Academic librarians are, after all, in the business of helping their patrons to access, interpret, and understand information; and a great deal of understanding on the part of the librarians themselves must necessarily take place before it can be passed on to the patrons. For a term to be introduced in the first place, at least one contributor to interdepartmental discussions must be expertly aware not only of its meaning, but also of its implications in the context of the overall communication structure. In order to build a "verbal Intranet" that would allow for an understanding of new terminology on all sides, this expert must be able to become a gatekeeper, allowing the flow of information to take more appropriate and productive paths.

Successful librarians are experts in their field who are able to shed their "expertness" (not expertise, but the attitude of expertise) in order to truly serve, and not alienate, their clientele. The problems that arise, for example, at the reference desk, when this does not happen, are legion and well documented. To arrive at well-informed technological decisions, this "expertness-shedding" skill must be turned inward. Librarians are gatekeepers and must be aware that the informational gate swings inward, toward our colleagues, as well as outward, toward the public.

\section{Notes}

1. Jonathan S. Intner, "A Meeting of the Minds: Effective Communication with Technical Staff," in Library Education and Leadership: Essays in Honor of Jane Anne Hannigan, ed. Sheila S. Intner and Kay E. Vandergrift (Meutchen, N.J.: Scarecrow Pr., 1990), 285-95.

2. Jean Aitchison, Language Change: Process or Decay? 3rd ed. (New York: Cambridge Univ. Pr., 2001), 120-30.

3. Ibid., 130 .

4. "Ask-a-Linguist: the Linguist List." Web page. Available online from http:// linguistlist.org/ ask-ling.

5. Suzette Haden Elgin, e-mail correspondence with authors, Jan. 9, 2001.

6. Deborah Ruuskanen, e-mail correspondence with authors, May 29, 2001.

7. Anne Marie Candido, "Fabricating and Prefabricating Language: Troubling Trends in Libraries," Journal of Academic Librarianship 25, no. 6 (1999): 433-38.

8. Attendees at a Windows 2000 workshop, Jan. 10-12, 2001, where one of the authors was also in attendance, verbally supplied these statements.

9. John Schwartz, "Language Heads Down the Rabbit Hole," New York Times, 10 Dec. 10, 2000 , sec. 4 , p. 6.

10. Stuart MacDonald, Information for Innovation: Managing Change from an Information Perspective (New York: Oxford Univ. Pr., 1988), 87-95.

11. Matt Holland, "The Change Agent," in Achieving Cultural Change in Networked Libraries, ed. Bruce J. Reid and William Foster (Brookfield, Vt.: Gower, 2000), 105-17.

12. John M. Conley and William M. O'Barr, Just Words: Law, Language, and Power (Chicago: Univ. of Chicago Pr., 1998), 2. 
13. Mark Warschauer, Electronic Literacies: Language, Culture, and Power in Online Education (Mahwah, N.J.: Lawrence Erlbaum Associates, 1999), 1.

14. Gregory A. Crawford and Ronald E. Rice, “Technology, Power and Structure: Developing a Model of the Effects of Automation on Liberal Arts College Libraries," Library and Information Science Research 19, no. 3 (1997): 265-300.

15. Hong $\mathrm{Xu}$, "Type and Level of Position in Academic Libraries Related to Communication Behavior," Journal of Academic Librarianship 22, no. 4 (1996): 257-66.

16. David Tuffley, "Enhancing IS Quality through Design-based Documentation Production," in The New SocioTech: Graffiti on the Long Wall, ed. Elayne Coakes, Dianne Willis, and Raymond Lloyd-Jones (London: Springer-Verlag, 2000), 126-33.

17. Sik Hung Ng and James J. Bradac, Power in Language: Verbal Communication and Social Influence (Newbury Park, Calif.: Sage, 1993), 88.

18. Paul Rux, “The Politics of Technology," Book Report 13 (Nov./Dec. 1994): 31.

19. Elayne Coakes, Dianne Willis, and Raymond Lloyd-Jones, "Graffiti on the Long Wall: A SocioTechnical Conversation," in The New SocioTech: Graffiti on the Long Wall (London: SpringerVerlag, 2000), 3 . 